\title{
A 2D DEM mono-pile model under combined loading condition
}

\author{
N. Duan \\ Department of Civil, Environment \& Geomatic Engineering, University College London, Gower Street, \\ London WC1E6BT, UK \\ Y.P. Cheng \\ Department of Civil, Environment \& Geomatic Engineering, University College London, Gower Street, \\ London WC1E6BT, UK
}

\begin{abstract}
This paper presents a 2D-Discrete Element Method (DEM) model that is used to study situations when vertical, lateral and combined loads are applied to a rigid mono-pile. At present, mono-pile foundations are widely used to support the tall and heavy wind turbines, which are also subjected to significant from wind and wave actions. A safe design must address issues such as rotations and changes in soil stiffness subject to these loadings conditions. Design guidance on the issue is limited, as well as the availability of laboratory and field test data. The interpretation of these results in sand, such as the relation between loading and displacement, relies mainly on empirical correlations to pile properties. Regarding numerical models, only data from Finite Element Method (FEM) can be found. They are not comprehensive enough, and most of the FEM results are quite sensitive to input parameters. The micro scale behaviour, such as, movement and densification of discrete particles near a pile could change the mechanism of the soil-structure interaction, hence, a DEM model was used in this paper to study the combined loading behaviour. By explicitly considering the particulate nature of the granular sand around a model pile, the micro-mechanism governing the complex soil structure was investigated. Verification of the DEM model was carried out by comparing simulation data against a model pile. Analyses of the model pile under pure vertical, pure lateral and combined loads are presented. A discussion about the permanent accumulated pile displacements caused by the combined loads is made, together with analyses on the sand micromechanics. They should offer insights on further research to optimise the design of mono-pile foundations to resist live loads in service.
\end{abstract}

\section{INTRODUCTION}

Pile foundations are widely used to support various types of structures for situations when shallow foundations undergo excessive settlements or have insufficient bearing capacity. These piles are not only used to support vertical loads, but also lateral loads and a combination of both vertical and lateral loads. According to the current practice, piles are independently analysed first for the vertical load to determine their bearing capacity and settlement and then for the lateral load to determine the flexural behaviour (Anagnostopoulos \& Georgiadis 1993). This approach, assuming the unrelated vertical and lateral pile response, is not comprehensive. Studying the interaction effects due to combined vertical and lateral loads for a systematic analysis, therefore it is essential.

The amount of literature on the effects of combined loads is scare. There is hardly any concerted effort to study the influence of vertical loads on the lateral response of piles, which is more appropriate to the situation of mono-pile. And it is very difficult to make clear the soil behaviour from the site experiments. The limited research based on analytical approaches (Goryunov 1973) revealed that for a given lateral load, the presence of vertical load increases the lateral deflection of the pile head. But laboratory testing Anagnostopoulos and Georgiadis (1993) suggested a decrease in the lateral deflection under the presence of vertical loads. Lee et al (2011) summarised all the results and proposed lateral deflection of the model pile head increased with increasing axial load.

The methods of analysis commonly used in predicting the behaviour of piles under pure axial loads could be categorized into: (a) subgrade reaction method (b) elastic continuum approaches, and (d) FEM (Karthigeyan et al. 2006, Karthigeyan et al. 2007). However, experimental and field investigations suggest a decrease in lateral deflection with the combination of vertical loads. Anagnostopoulos \& Georgiadis (1993) attempted to explain this phenomenon through an experimental model supported 
by 2D FEM analysis. They reported that the modified state of the soil stresses and the local plastic volume changes in the soil mass under the combined vertical and lateral loads cannot be taken into account by the conventional subgrade reaction analysis, nor the elastic half space methods.

However there are limitations on FEM, as soil is not always a continuum. The particles of soil may slide, rotate, deform or crush; some of them may also move across the space through the voids, or they lock in certain locations forming soil arch. There are example features that cannot be modelled easily by FEM. In view of the above issues, the 2D DEM was used in this research to analyse the combined loading effect, and the present paper focuses on the influence of axial load on the lateral response of a pile. The details of model setup, the parameters used and the verification of the model against laboratory testing cases are presented. Combined loading tests were performed for axial loads equal to $0 \%, 33 \%$, $66 \%$, and $83 \%$ of the ultimate axial capacity (defined as the load corresponding to a settlement equal to $10 \%$ of the pile diameter) of the model pile.

\section{NUMERICAL MODEL}

The DEM is referred to, by Cundall \& Strack (1979), as the particular discrete element scheme that uses deformable (soft) contacts and an explicit time-domain solution of the original equations of motion. The Particle Flow Code in 2-Dimensions (PFC2D) is a programming code which is developed by Itasca. This software uses the DEM to simulate the movement and interaction of circular particles and observe their strain and fracturing behaviour, and all DEM programs allow finite displacements and rotations of discrete bodies, including complete detachment (Cheng 2004). PFC2D can model either bonded (cemented) or unbounded (granular) group of particles (Itasca 2008), and also particles of any shape using the clump logic. Therefore it is a powerful tool to simulate complex problems in solid mechanics, rock mechanics, and granular flow. At the same time, it allows for a detailed study of the micro-mechanics, such as the force networks formed by a granular media.

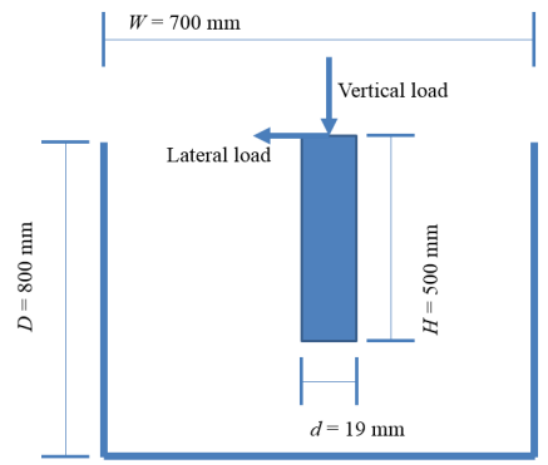

All DEM analyses in this investigation were performed using the 2D PFC program. Figure 1 shows a sketch for analysis of pile-soil interaction and Figure 2 gives the particles size distribution. The pile was treated as a rigid material in view of high rigidity of a typical monopile, hence the consideration of bending moment was ignored. The vertical load and lateral load was applied to the ground surface on the top of pile.

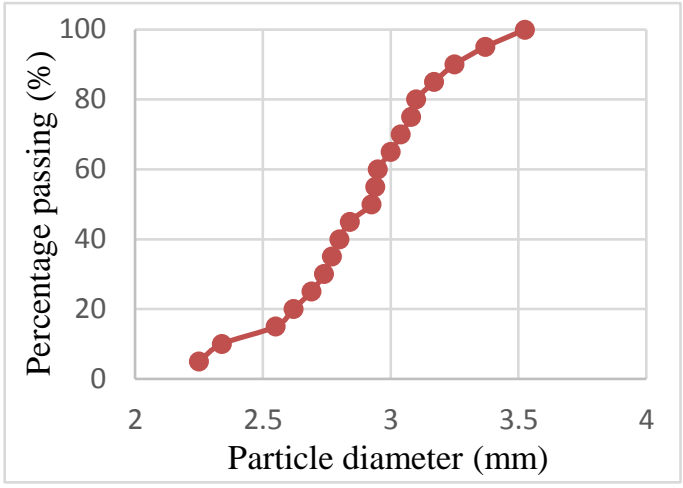

Figure 1 Particles size distribution in DEM simulation

\subsection{Validation of the numerical model employed in the program}

\subsubsection{Procedure of model generation}

The validity of the numerical model was verified by checking the pile load test data against a comprehensive published case. The laboratory tests performed by Anagnostopoulos \& Georgiadis (1993) were a single pile under both vertical and lateral loads applied to the pile head at ground elevation.

In the 2D PFC model, the boundary was first set in such a way that the size of the model was the same as that of Anagnostopoulos \& Georgiadis (1993). Rigid walls were used to model the boundary. The second step was the generation of particles. The particles were given properties as showed in Table 1. At the first stage, when the initial average porosity was nearly reached, the model was cycled to equilibrium. At the second stage, the gravity was added, and the PFC model was cycled to equilibrium again. This moment, the porosity was the final average porosity. At the third stage, before the pile was formed, the particles inside the same area were deleted. In this research, "clump" was used to model the rigid pile with a finite surface roughness. The system was then cycled to equilibrium again with the pile in place. Vertical and lateral forces were then applied to the top of pile directly.

\subsubsection{Input parameters}

Table 1 shows the model parameters. From the 2D PFC manual, the particle normal stiffness is equal to twice the particle Young' modulus. 
Table 1 Input parameters for DEM simulations

\begin{tabular}{|l|r|}
\hline Density of sand particles $\left(\mathrm{kg} / \mathrm{m}^{3}\right)$ & 2650 \\
\hline Particle diameters, $d(\mathrm{~mm})$ & Fig 2 \\
\hline Sand grain size, $d_{50}(\mathrm{~mm})$ & 2.925 \\
\hline Friction coefficient of the particles $\mu(-)$ & 0.5 \\
\hline Sand Young's Modulus, $E_{\mathrm{p}}(\mathrm{Pa})$ & $1 \mathrm{e} 7$ \\
\hline Contact normal stiffness of particles, $k_{\mathrm{n}}(\mathrm{N} / \mathrm{m})$ & $2 \mathrm{e} 7$ \\
\hline Particle stiffness ratio $\left(k_{\mathrm{s}} / k_{\mathrm{n}}\right)$ & $2 \mathrm{e} 7$ \\
\hline Contact normal stiffness of walls, $k_{\mathrm{n}}(\mathrm{N} / \mathrm{m})$ & 0.28 \\
\hline Initial average porosity & 0.19 \\
\hline Final average porosity & 18 \\
\hline Bulk unit weight $\gamma_{\text {bulk }}\left(\mathrm{kN} / \mathrm{m}^{3}\right)$ & 0.8 \\
\hline Coefficient of earth pressure at rest, $\mathrm{K}_{\mathrm{o}}(-)$ & \\
\hline
\end{tabular}

\subsubsection{Lateral stress distribution}

Figure 3 shows that the stress distributions acting on the pile and on the far wall are similar. It means this model is reasonable. At $0.5 \mathrm{~m}$ depth, the line of pile seemed a significant fluctuation, the reason was that there was the location of pile end. When the area of sand was deleted for the pile installation, the area was a little smaller than the pile. Therefore, this area might be experience a tight condition. Using the trendline shown in Figure 3 and the bulk unit weight calculated from the average porosity of the particles, the coefficient of earth pressure at rest is approximated to be 0.8 .

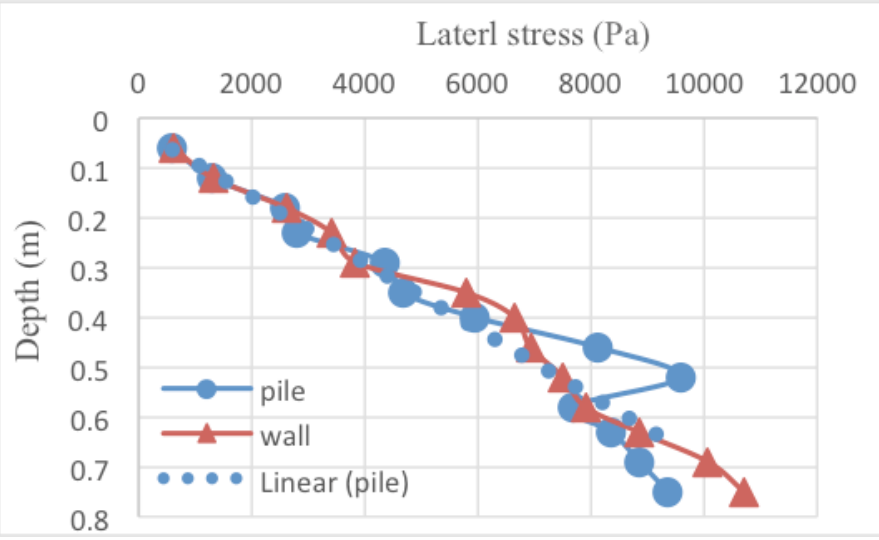

Figure 3 Lateral soil stress distribution in front of the pile at static state

\subsubsection{Displacement VS Force}

The sequence of the load application used in the current DEM analysis is the same as that used in the laboratory tests (Anagnostopoulos \& Georgiadis 1993). The comparison between the test data and the predicted results of piles under pure vertical load and combined vertical and lateral loads are shown in Figure 4. Figure 4(a) shows that the comparison is very good both at small and larger load levels for vertical response of pile. For the lateral responses of the pile, shown in Figure 4(b), the comparison is good at a smaller horizontal load, but the percentage difference increases at the larger load levels. Up to a lateral displacement equal to $0.33 \%$ of the pile diameter, the difference between the measured and predicted pile loads is less than $6.25 \%$. At a larger displacement equal to $0.84 \%$ of the pile diameter, the difference increases to approximately $54.28 \%$. This deviation is acceptable in view of the many uncertainties in choosing the sand properties in the analysis, and also due to the rigid assumption of the monopile model. And the other main reason is that the actual experiment was performed in threedimensions. Due to the good match at the relationship between vertical load and axial displacement, it is concluded that the numerical scheme adopted in the present investigation should be capable of modelling the pile-soil interaction under pure vertical load, lateral load, and a combination of vertical and lateral loads.

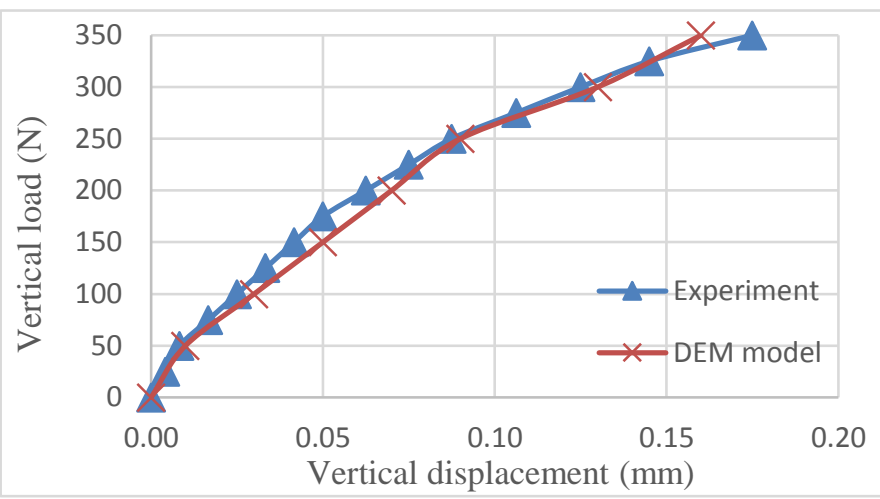

(a)

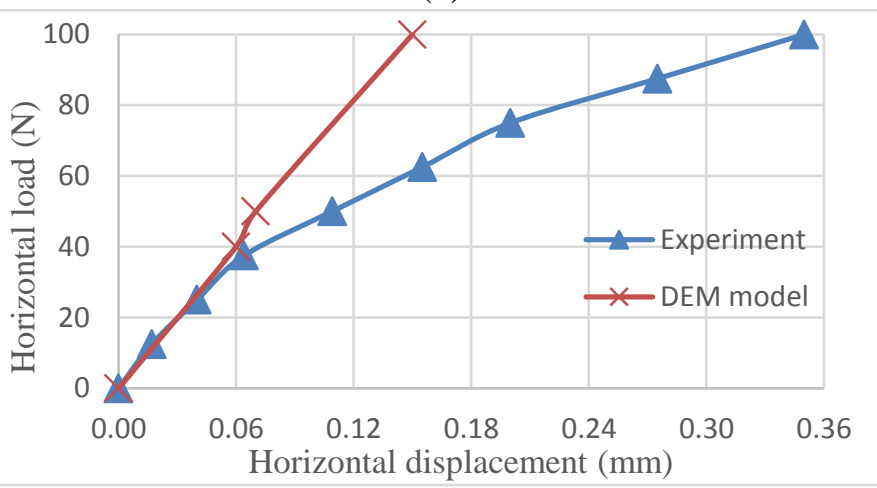

(b)

Figure 4 Comparison of DEM predicted vertical and lateral response of pile with experimental test data of Anagnostopoulos \& Georgiadis (1993): (a) vertical response of pile; (b) lateral response of pile

\section{COMBINED LOADS RESULT AND DISCUSSION}

The analyses were performed to study the influence of the vertical load on the lateral response of pile. A series of analyses have been carried out to study the behaviour of piles under pure lateral loads and the influence of different levels of vertical load 
on the lateral responses of piles. The details of the PFC2D model and the results are discussed in this section.

\subsection{Macroscopic load displacement data}

In this study, a particular vertical load was applied first, and then, lateral loads were applied incrementally to the pile head and then the model was carefully cycled to equilibrium at each step while the vertical load was kept constant.

The ultimate vertical load ( $\left.\mathrm{V}_{\text {ult }}\right)$ capacity of a single pile was evaluated a priori by separate numerical analyses. Then the response of piles under combined loading was analysed separately with the vertical load equal to zero (pure lateral load case), $0.33 \mathrm{~V}_{\text {ult }}$ and $0.66 \mathrm{~V}_{\text {ult }}$. The ultimate vertical load capacity was estimated as $1200 \mathrm{~N}$, and the ultimate horizontal load $\left(\mathrm{H}_{\text {ult }}\right)$ capacity of a single pile was $400 \mathrm{~N}$.

Figure 5 plotted the different curves of model pile head lateral deflection versus lateral load for the combined loading simulations under axial load $\mathrm{V}$ equal to $0 \%, 33 \%$ and $66 \%$ of the ultimate axial load $\mathrm{V}_{\text {ult }}$, where the value of $\mathrm{V}_{\text {ult }}$ was obtained from the pure axial loading test. $0 \mathrm{~V}_{\text {ult }}$ means that there was no axial loading applied to the pile head. It is seen from this figure that the vertical load has only a marginal influence on the lateral response of pile.

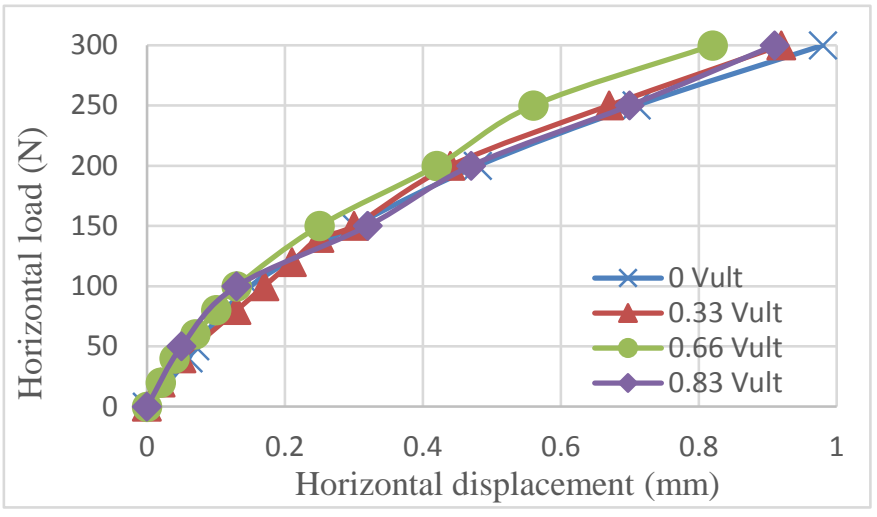

Figure 5 Lateral load-deflection behaviour of a pile in sands

The results shown in Figure 5 is very similar to the FEM reults of Karthigeyan et al. (2006). Compare with the FEM's outcome, the trend of DEM model is similar and resonable. In gernal, the larger is the vertical load (up to $0.66 \mathrm{~V}_{\text {ult }}$ ), the smaller is the horizontal displacement induced by the horizontal load. The interesting phenomenon in Figure 5 is the line of $0.83 \mathrm{~V}_{\text {ult. }}$ This line is not behind $0.66 \mathrm{~V}_{\text {ult }}$, but is between 0Vult and 0.6Vult. This is the same as Karthigeyan et al. (2006); the line of $0.83 \mathrm{~V}_{\text {ult }}$ is in front of 0.66Vult.

Since the lateral defection of the model pile head decreases with increasing axial load, this means that the presence of an axial load is good to the lateral capacity of driven pile in sand. Therefore, it is usually not necessary to consider the effect of axial loads in the design of laterally loaded pile in sand.
Following Karthigeyan et al. (2006), the Percentage Improvement in lateral Capacity (PIC) was defined to measure the influence of vertical loads on the lateral response of piles in sands:

$$
P I C=\frac{L D N V-L D W V}{L D N V} \times 100
$$

where 'LDNV' is the Lateral load Displacement under pure lateral load (with No Vertical load), 'LDWV' is the Lateral load Displacement With Vertical load. The PIC analyses have been summarized in Table 2.

It shows clearly that the lateral capacity of pile in sand improves in general under the presence of vertical loads. The PIC increases (e.g. from $6.1 \%$ to $14.3 \%$ at a lateral load of $0.75 \mathrm{H}_{\text {ult }}$ ) when the axial load increases from $0.33 \mathrm{~V}_{\text {ult }}$ to $0.66 \mathrm{~V}_{\text {ult }}$. When comparing the same level of lateral load, the improvement in lateral capacity becomes bigger under a larger vertical load. It proves that the improvement of pile lateral capacity is generally in proportion to the vertical load. And the increase of horizontal capacity of pile has been obvious even when the vertical and horizontal load are both small.

Table 2 Percentage Improvement in the lateral Capacity (PIC) with respect to different vertical load levels

\begin{tabular}{|l|l|l|l|l|}
\hline $\begin{array}{l}\text { Vertical } \\
\text { load in } \\
\text { terms of } \\
V_{\text {ult }}\end{array}$ & $\begin{array}{l}\text { Lateral } \\
\text { deflection } \\
(\mathrm{mm}) \text { at } \\
\text { lateral } \\
\text { load of } \\
0.5 H_{\text {ult }}\end{array}$ & $\begin{array}{l}\text { PIC at } \\
\text { lateral } \\
\text { load of } \\
0.5 H_{\text {ult }}\end{array}$ & $\begin{array}{l}\text { Lateral } \\
\text { deflection } \\
(\mathrm{mm}) \text { at } \\
\text { lateral } \\
\text { load of } \\
0.75 H_{\text {ult }}\end{array}$ & $\begin{array}{l}\text { PIC at } \\
\text { lateral } \\
\text { load of } \\
0.75 \\
H_{\text {ult }}\end{array}$ \\
\hline 0 & 0.48 & - & 0.98 & - \\
\hline 0.33 & 0.44 & $8.3 \%$ & 0.92 & $6.1 \%$ \\
\hline 0.66 & 0.42 & $12.5 \%$ & 0.82 & $14.3 \%$ \\
\hline
\end{tabular}

This impact of vertical load may be attributed to the higher vertical soil stress develop in the soil along the pile surface, which in turn leads to higher lateral stresses acting on the pile. This phenomenon will be explored further in the following sections.

\subsection{Lateral soil stress}

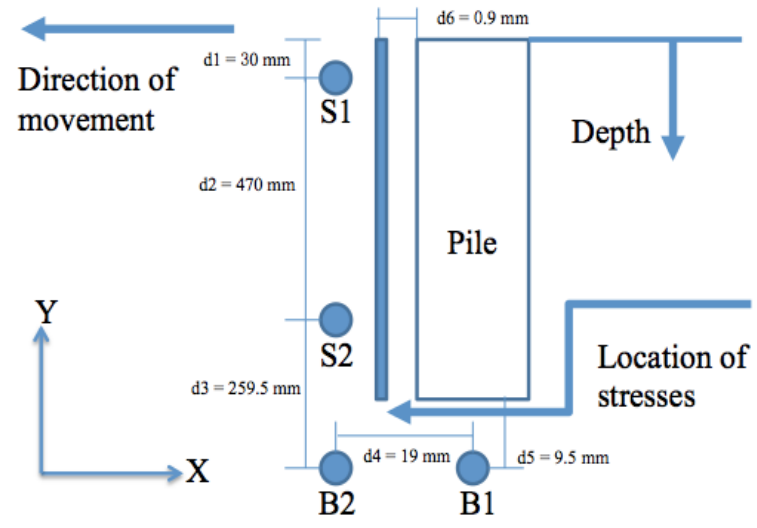

Figure 6 A sketch showing the locations of lateral stress records and trace particles 
Figure 6 shows the locations of the four traced particles (S1, S2, B1, B2), and also the locations in front of the pile, at which the lateral soil stress was measured. The distributions of the lateral soil stresses in front of the pile at a specific lateral deflection of $0.75 \mathrm{H}_{\text {ult }}$ are shown in Figure 7 . The X-direction and $\mathrm{Y}$-direction movements of the traced particles were recorded and are shown in Figure $8 \& 9$.

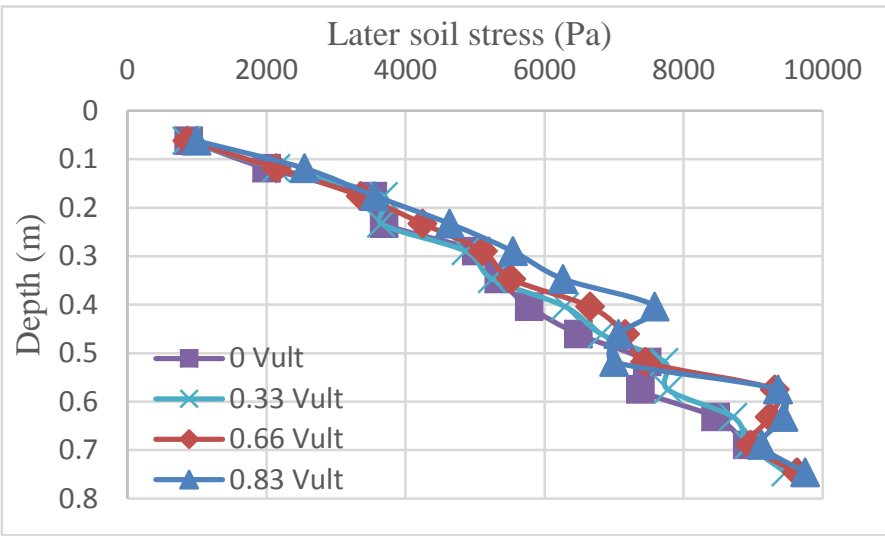

Figure 7 Distributions of lateral soil stress in front of the pile at a lateral deflection of $0.75 \mathrm{H}_{\text {ult }}$ in sand

It is clearly found in Figure 7 that the lateral soil stresses are affected by the existence of vertical loads. The static state was a reference, showing the stress distribution when the pile was not under any load. Above $0.2 \mathrm{~m}$ depth, the lateral stress did not increase with existence of vertical load, in fact the lateral stress decreases a little. Below $0.2 \mathrm{~m}$ depth, the horizontal stress increases. This increase happens only between $0.2 \mathrm{~m}$ and $0.45 \mathrm{~m}$ depth along the pile. Below $0.7 \mathrm{~m}$ depth under the pile, the lateral stress remains more or less the same with the existence of larger vertical load. Above $0.4 \mathrm{~m}$ depth where also was the centre of pile rotation, the lateral stress increased with the rising vertical loads. The interesting phenomenon took place at around $0.5 \mathrm{~m}$ depth. When the pile was pushed under different vertical loads, the lateral stress still did not change a lot. However, the bigger vertical load was adding, the smaller lateral stress was appeared. With the existence of axial load, generally a larger lateral stress was required, and so a larger stress distribution was developed along the pile, in order to move the pile head to the same level of deflection of $0.75 \mathrm{H}_{\text {ult }}$. This implies a higher lateral capacity. Figure 7 is related to Figure 5 , it can be used to explain the macro phenomenon from the micro mechanics. This is also similar as Karthigeyan et al. (2006).

\subsection{Microscopic movement of traced particles}

Further analysis is performed by tracing the $\mathrm{X}$ plane and Y-plane displacements of four representative particles in this pile model, the results are shown in Figure $8 \&$ Figure 9. According to the pile model in Figure 6, Particle B1 is located immediately under the pile in the pile's vertical central axis, and the particle B2 is chosen at the same Y-level of B1. Particle S2 is located slightly above B2 but along the pile shaft. Particle S1 is also along the pile shaft but closer to the soil surface.

Figure 8 shows the variations on the displacements of the four particles in both directions under pure lateral load. In Figure 8, X-plane means the horizontal direction and Y-plane means the vertical direction. Figure 8(a) is the $\mathrm{X}$-direction summary of all of the four particles traces. It can be seen that only particle S1 moved to left, although the pile was moved to left, all other particles moved to the right. This is because S2, B1 and B2 are all near or below the centre of rotation of the pile. Form the record data, the centre of rotation of the pile was not a constant but varied within a small range at around $4: 1$, the length above the centre is four times bigger than the length under. It can be seen that the particle S2 along the pile moved more than $\mathrm{B} 1$ and $\mathrm{B} 2$ under the pile. And particle B2 moved more than B1 due the distance away from the centre of the pile.

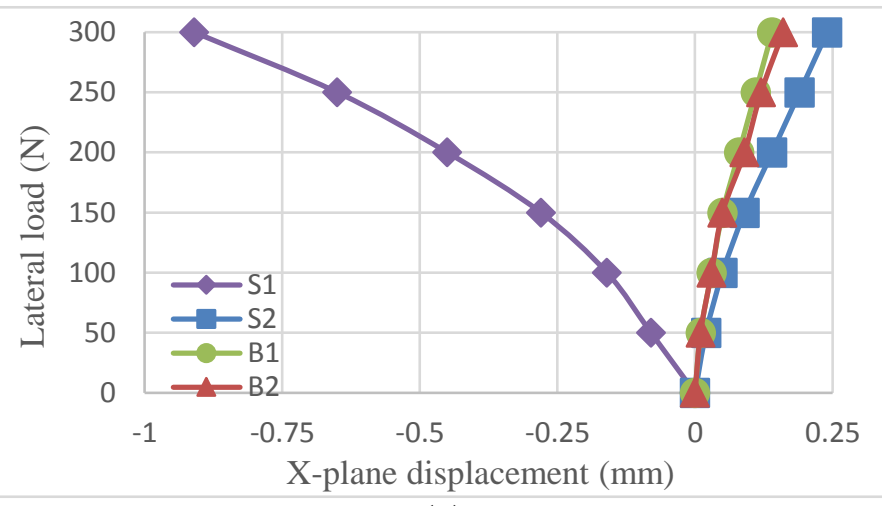

(a)

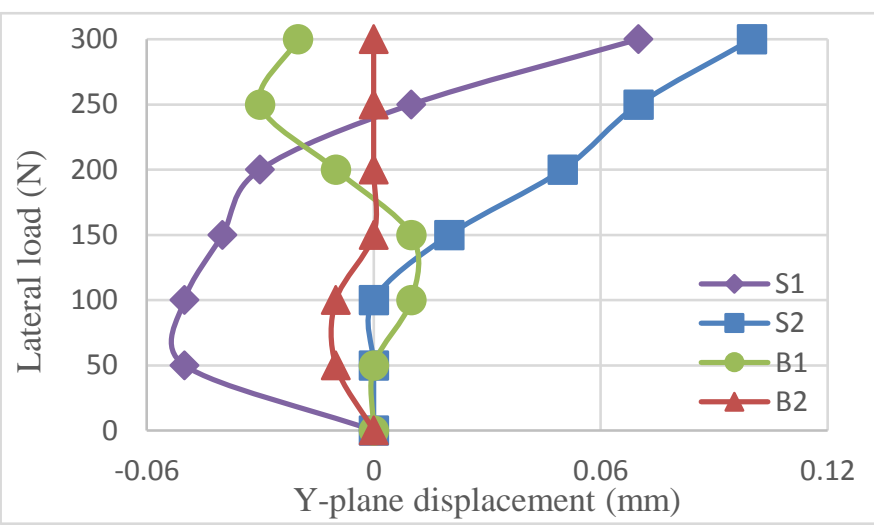

(b)

Figure 8 Displacement of traced particle under pure lateral load (a) X-displacement of four particles, (b) $Y$-displacement of four particles

In Figure 8(b) showing the vertical displacements, particles B1 and B2 remain nearly unmoved. S2 moved upwards. S1 moved downwards first and then moved upwards as well. The depth of B1 and B2 were same and under the pile, perhaps these two particles were too deep, so the two particles B1 and B2 were not affected too much. In contrast, S1 was situated near the soil surface, it shows that the soils settled and then followed by dilation. And the movement of particle S2, above B1 and B2, was mainly dominated by dilation.

However, a different the lateral pile response was observed with a vertical load of $0.33 \mathrm{~V}_{\text {ult. }}$ The results 
are shown in Figure 9. The X-direction displacements of three particles (S1, B1, B2) are now similar. In the vertical direction from Figure 9(b), all particles S2, B1 and B2 moved downwards. S2 settled with vertical load instead of dilated. B1 was immediately under the pile so settled more than B2. S1 near the surface moved slightly downwards and then slightly upwards. In general, the movement of particle $\mathrm{S} 1$ followed a similar trend regardless of vertical load. However, all other particles were affected much by vertical load. These settlements of the particles near the pile end should increase the density of the soil around the pile, leading to a higher capacity.

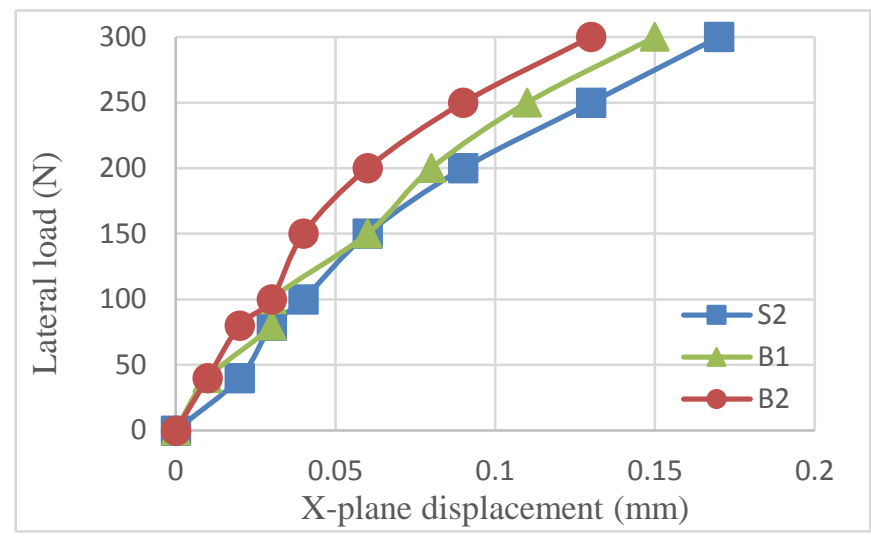

(a)

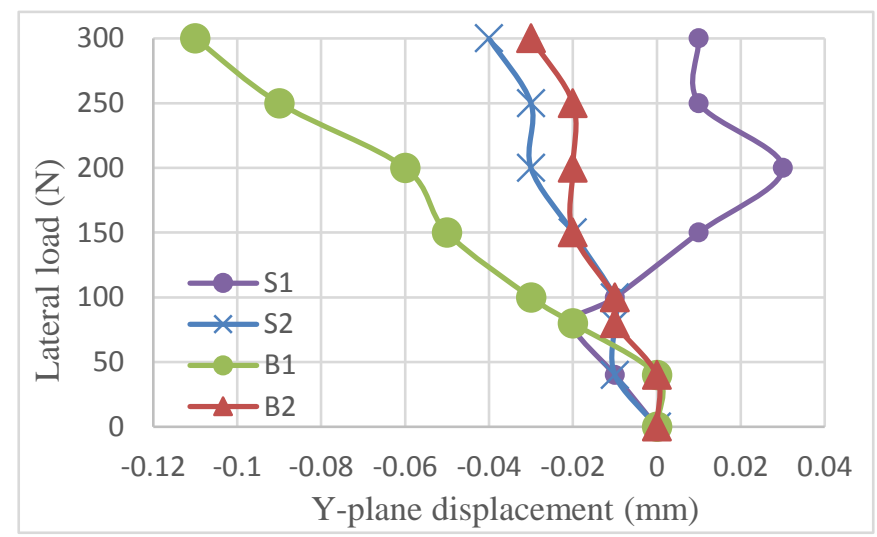

(b)

Figure 9 Displacements of traced particle under 0.33 Vult (a) Xdisplacement of three particles (b) Y-displacement of four particles

Tracing representative particle displacements demonstrates well that pile penetration is a dynamic process and shows how the sand has been influenced during pile penetration.

\section{CONCLUSION}

In this research, DEM simulations have been adopted in analysing the phenomenon of a rigid pile under the combined loadings conditions from the microscopic and the macroscopic points of view. The main conclusions can be drawn as follows:

1. The vertical load has a profitable influence on the lateral response of piles embedded in sand. However, the influence depends on the sequence of loading which is applied in this paper.
2. The maximum percentage improvement in lateral capacity is up to $14.3 \%$ in this model. Even at the bigger lateral load condition, the lateral capacity was improved at $14.3 \%$. This is attributed to the decline of additional lateral soil stresses in front of the pile.

3. The test results imply that it is conservative to design piles assuming that there is no interaction between axial and lateral loads. The test results also show that the larger the axial load, the bigger the ultimate lateral load capacity of the model pile subjected to combined loads. Therefore, the consideration of the effect of axial loads in the design of laterally loaded piles driven in sand is not necessary.

4. This DEM method may provide a foundation for the further study of the micro mechanisms of soil variation around a pile in the course of combined loads. The traces of particles movements have showed that there were obvious settlements of the soil particles near the bottom of the pile when it is vertical load. This should lead to soil densification and hence an increase in the lateral pile capacity under the combined loading condition.

Further data regarding the impact of boundary condition, pile stiffness, aspect ratio of pile and the density of soils, etc., will be shown in the long version of this paper.

\section{References}

Anagnostopoulos, C. \& Georgiadis, M. 1993. Interaction of axial and lateral pile responses. J Geotech Eng, 119(4), 793798.

Cheng, Y. 2004. Micromechanical investigation of soil plasticity. $\mathrm{PhD}$ thesis, Cambridge University.

Cundall, P. \& Strack, O. 1979. A discrete numerical model for granular assemblies. Geotechnique, 1, 47-65.

Goryunov, B. 1973. Discussion on analysis of piles subjected to the combined action of vertical and horizontal Loads. J Soil Mech Foundation Eng, 3, 6-8.

Itasca, 2008. PFC User Manual, Version 4.0.

Karthigeyan, S., Ramakrishna, V.V.G.S.T. \& Rajagopal, K. 2006. Influence of vertical load on the lateral response of piles in sand. Computers and Geotechnics, 33(2), 121-131.

Karthigeyan, S., Ramakrishna, V.V.G.S.T. \& Rajagopal, K. 2007. Numerical Investigation of the Effect of Vertical Load on the Lateral Response of Piles. J Geotech Geoenviron Eng, 133(5), 512-521.

Lee, J., Prezzi, M. \& Salgado, R. 2011. Experimental Investigation of the Combined Load Response of Model Piles Driven in Sand. Geotechnical Testing Journal, 34(6), 1-15. 